\title{
Virtual museum in the system of informal education (based on sports materials)
}

\author{
Olga Fedotova ${ }^{1}$, Vasilij Zhurakovskij ${ }^{2}$, Pavel Ermakov ${ }^{3}$, Ilia Cherkashin ${ }^{4}$, and Elena \\ Cherkashina $^{4}$ \\ ${ }^{1}$ Don State Technical University, 344003, Rostov-on-Don, Russia \\ ${ }^{2}$ National Training Foundation, 125009, Moscow, Russia \\ ${ }^{3}$ Southern Federal University, 344000, Rostov-on-Don, Russia \\ ${ }^{4}$ North-Eastern Federal University, 677027, Yakutsk, Russia
}

\begin{abstract}
The article raises the problem of using the educational potential of virtual museums. It is noted that virtual museums are a new organizational form of the modern system of informal education. Thanks to the availability and openness of museum funds, it becomes possible to acquaint young people with the artifacts of culture and social life. The exposition fund of the virtual museum of bookmarks created in Germany is analyzed. The thematic field "sport" is chosen as the object of research. Based on content analysis, the frequency of manifestation of this concept is revealed. On the basis of cluster analysis, the belonging of the exhibits to various sections of the virtual museum is established. It is concluded that sport is presented as a subject of three clusters 1) financial savings for sports, 2) advertising lifestyle and sporting goods and 3) world-class sporting events. The assessment of the peculiarities of presentation of the content of bookmarks on the subject of sports creolized texts is given.
\end{abstract}

\section{Introduction}

Our contemporarylives in a dynamic world based on a complex balance of interests. A person is influenced by flows of multidirectional information, which has different value, usefulness and relevance. Often, a person does not evaluate information perceived in the context of various types of communication as an objectified desire of certain social actors. Social actors can own and regulate the dissemination of information. Depending on the situation, they aim to induce to assimilate some non-material forms of content movement, generated by each in the form of concepts, representations and categories of cultural, social, economic, ideological level. A person does not think about the fact that people are subjects of culture and representatives of the target audience, which is purposefully influenced by the means of non-personalized communication. No one disputes the fact that a person at any age is directly or indirectly influenced by formative influences that induce him to a certain style of thinking and behavior algorithm $[1,2]$.

The concept of "informal education" has been introduced into the scientific and pedagogical apparatus. It captures the many opportunities for broadening one's horizons

\footnotetext{
*Corresponding author: fod1953@yandex.ru
} 
and obtaining an education outside the standard educational environment. This concept also includes various types of activity of individuals in the cultural and educational environment and leisure activities. It is recognized that informal education has a contextual character. It uses the socio-cultural potentials of society, which each person can turn into effective factors of their development. In the scientific tradition, the phenomenon of implicit molding influence is enshrined in the term "hidden pedagogy" [3,4]. This term is both a conceptual metaphor and, along with other theoretical conceptualizations, a theoretical projection of implicit formative effects. In this regard, one should not underestimate the role of museums in collecting, exhibiting and researching monuments of spiritual and material culture of the past. In modern society, based on the development of its technical and technological potential, new concepts of museums appear and are being implemented. Museums exist not only in the form of cabinet of curiosities and exhibition galleries [5,6], but also virtually, in the Internet space $[7,8]$. This makes it possible to expand the scope of educational activities and make the cultural heritage open to the public and accessible $[9,10]$.

In Germany there is a unique electronic museum, which contains original exhibits bookmarks (bookmark, das Lesezeichen), issued in Germany, Federal Republic of Germany and German Democratic Republic in the 19-th and 20-th centuries. The German Bookmark Museum is located at http://www.lesezeichenmuseum.de. Its funds amount to more than 20,000 exhibits. Bookmark is considered as a special element of book design [11], creolized text [12], attribute of reading culture [13], collectible [14]. Bookmark is a sheet edition intended for nesting between pages in order to quickly find a place where reading was interrupted or to which you need to return. Bookmark text is also used for advertising. In addition to the advertising purpose in the modern socio-cultural space, the opinion has been established that a bookmark can have a didactic meaning. The bookmark can be considered as fun and / or craft, in the process of making which children and adults develop teamwork skills, develop an aesthetic sense and work skills.

\section{Methodology and methods}

The purposeof the research is to establish the intentions of bookmark producers to use indirect factors of formative influence as predictors of the popularization of a certain lifestyle. It seems appropriate to analyze the thematic bookmarks presented in the museum, the plots of which are directly or indirectly addressed to sports issues.

The hypothesis of the research is reduced to the assumption that the choice of plots and facts placed on the bookmark reflects the intentions of the communicator (here: the artist acting in the interests of the manufacturer) to popularize certain aspects of sports reality. If we select from the general exposition array of the museum exhibits that reflect sports topics, and systematize the sample according to certain criteria, then it will be possible to find the preferences of advertisers in the field of selection of factors of shaping influence.

Empirical research source: a collection of sports bookmarks presented in various sections of the virtual museum. The total number of exhibitsis 786 .

The methodology consists in the use of methods of theoretical and empirical research, including analysis, interpretation of content, comparative analysis, content analysis and cluster analysis [15]. When conducting a content-analytical study, we were guided by the regulatory requirements, which allows us to establish the frequency of manifestation of features of interest to the researcher on a different empirical array $[15,16]$. The category of content analysis - semantic units denoting empirical signs of the concept of "sport in human life". The unit of account was a bookmark with an inventory number, which made it possible to consider it as a museum exhibit.

The coding tables of the EXCEL program were used. The tools of this program were used to visualize the results obtained [17]. 
The research was carried out in three stages. The task of each stage is presented in the corresponding section.

\section{Results}

At the first stage of the research, the problem of determining the ratio of the total number of exhibits to their number, reflecting the sports theme, was solved.

Based on the counting of all museum storage units, a distribution polygon was obtained (see Fig. 1).

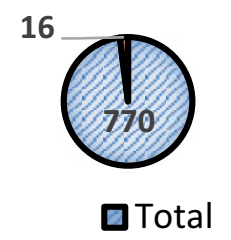

Fig. 1. Distribution of exhibits on sports topics in the general exposition fund of the virtual museum.

As shown in the Figure 1, sports-related exhibits make up a negligible share of the total empirical array. As a percentage, the number of sports-related exhibits is $2 \%$. At the same time, it should be noted that the period under review (from 1890 to the present) was marked by a revival of interest in sports. The end of the 19th century was marked by the revival of the Olympic movement and the holding of the Olympiads, which were not held only in 1916 (World War I), 1940 and 1944 (World War II). The thematic range is of certain interest from the standpoint of content selection in accordance with the headings of the virtual museum.

The second stage of the research is devoted to determining the thematic spread in the distribution of exhibits by headings of a virtual museum. The results are shown in Figure 2.

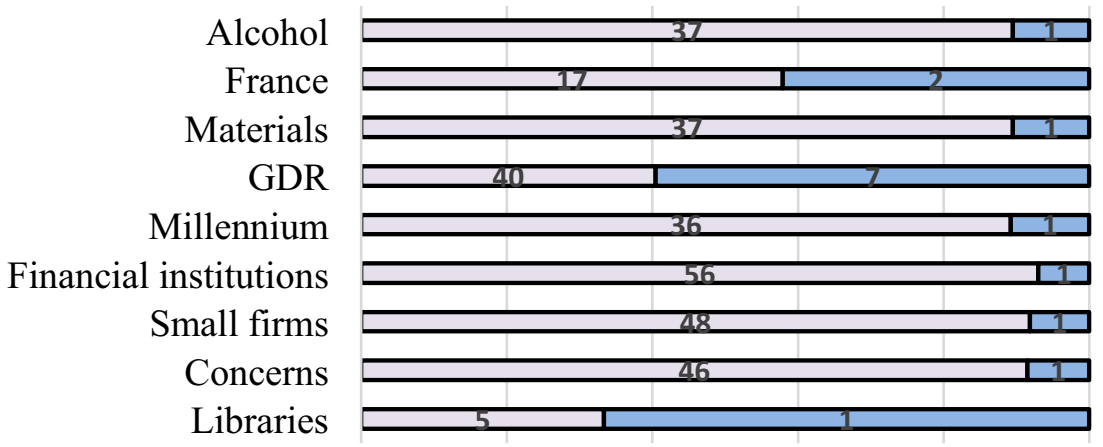

口total $\square$ sport

Fig. 2. Distribution of exhibits on sports topics by headings of the museum. 
The histogram shows the distribution of the empirical array of sports topics within the headings of the virtual museum. As follows from the data presented in Figure 2, the number of exhibits in different headings ranges from 1 to 7 in the total volume of placed bookmarks. The exposition headings of the virtual museum are not systematized according to a specific criterion and reflect the most diverse aspects of social reality. Among them are countries (GDR, France), financial and production units (financial institutions, small firms, concerns), cultural institutions (libraries), time units (millennium), materials and alcoholic beverages. Bookmarks promote lifestyle (see Fig. 3).

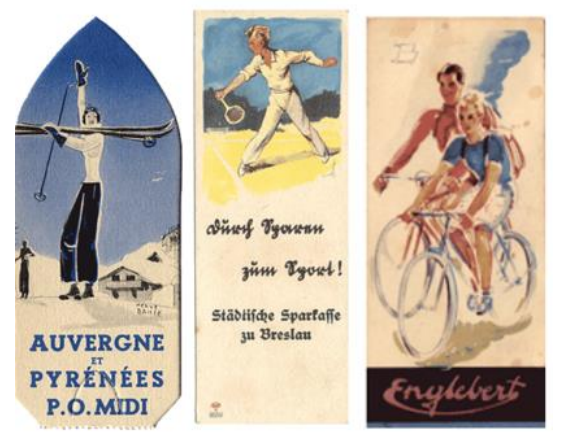

Fig. 3. Using sports bookmarks as a way to promote lifestyle.

When analyzing lifestyle issues, there is a tendency to represent socially prestigious, non-mass sports (skiing in European winter resorts, tennis, cycling).

The study of the inscription of German bookmarks leaves no doubt that elite sports are an expensive pleasure, as evidenced by the slogan on the bookmark with the image of the tennis player "DuchSparenzum Sport" (to sport through savings).

A bookmark is an effective advertising medium (see Fig. 4).

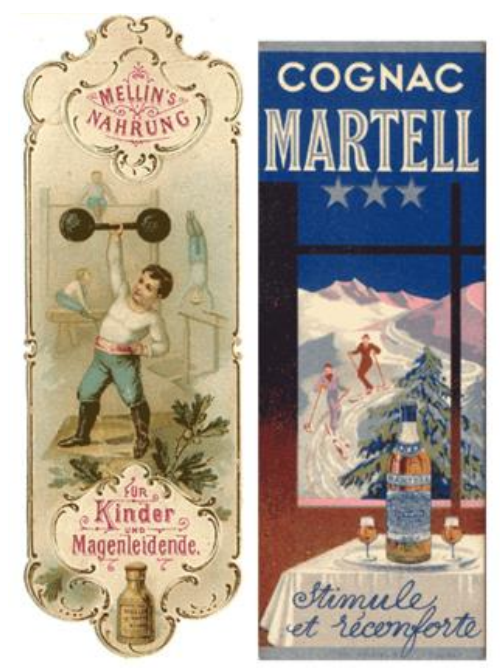

Fig. 4. Sports bookmarks used for food advertising. 
As shown in Figure 4, any food product can be advertised. One of the oldest exhibits in the virtual museum, dating back to 1890 , features an advertisement for baby food. The creolized text represents a strong child made like this by consuming Mellin food. The child performs a difficult exercise - lifts the barbell with one hand. In the background are images of the same child who performs gymnastics exercises - exercises on uneven bars, a crossbar, on a horse. This is indirect evidence that baby food from the company is useful and all muscle groups are well developed.

The image of graceful ladies engaged in winter sports (Alpine skiing) is used to advertise the cognac produced by one of the oldest cognac houses, Martell.

At the third stage of the research, cluster analysis was carried out. The subjects of all the exhibits of the virtual museum on sports problems can be presented in the form of three clusters (see Fig. 5).

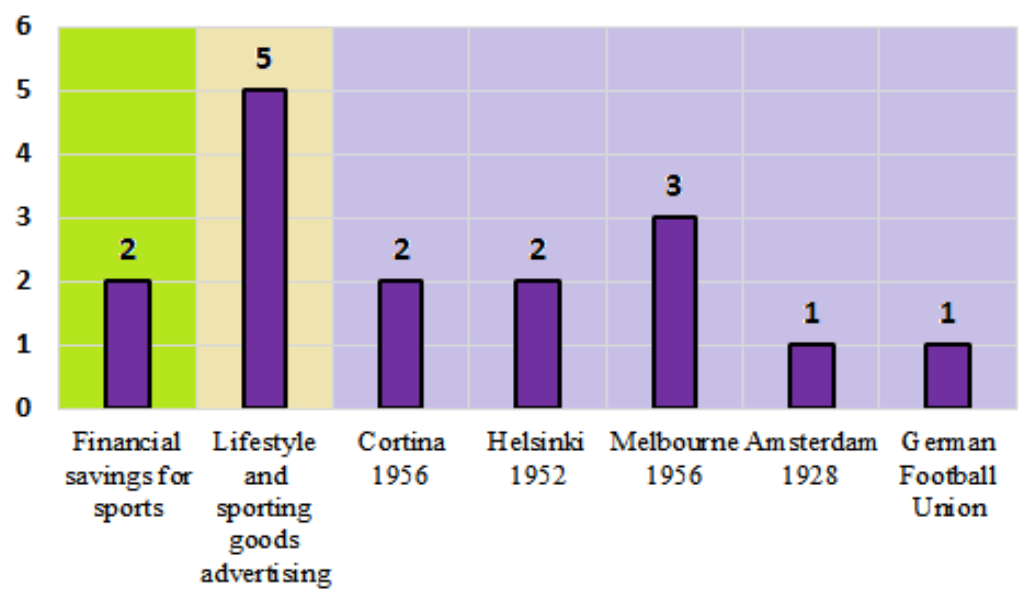

Fig. 5. Thematic clustersreflecting sports issues.

As noted earlier, the total number of thematic exhibits is 16 units. According to the criterion "theme", they clearly reflect such positions as 1) financial savings for sports, 2) advertising lifestyle and sporting goods and 3) world-class sporting events. The third cluster is represented exclusively by exhibits dedicated to the champions of the Olympiads. All of them are placed in the heading "GDR". Figure 5 shows that sporting events related to the Olympic Games of 1928, 1952 and 1956 are reflected, as well as the entry into the German Football Association in 1954. The exhibits show images not only of athletes from the GDR, for example, the first Olympic champion from the GDR, Wolfgang Behrendt, who won the gold medal at the 1956 Summer Olympics and became the first Olympic champion for East Germany in boxing flyweight [18]. The exhibits are also represented by Soviet, American and Austrian athletes.

\section{Conclusion}

A bookmark as an artifact of culture can be viewed as a latent factor of formative influence, combining elements of an instructive text and didactic illustration. The bookmark connects space and time, sets spatial and temporal markers. It links the time of reading with the time of life. The potential of any pictorial publication implicitly includes the idea of reflecting the educational and civic ideal of a particular era. Bookmarks are actively used as a means of informal education and as advertising media. Nevertheless, in our hypothetical view, the 
sports theme, realizing the educational function in the sphere of the culture of physical activity, is mainly one of the directions of the marketing policy implementation.

The appeal to sport as a cultural value and the promotion of sporting achievements in "pure form" is presented only in the publishing products of the GDR. This country did not use sports as a pretext for propaganda or advertising.

In general, it can be stated that the analysis of bookmarks as exhibits of a virtual museum, considered as an empirical array of research, made it possible to clarify the intentions of both communicator artists and their customers in terms of popularizing information on various aspects of the formation and implementation of value orientations of readers of all typological groups included in the world of book culture.

\section{Acknowledgements}

The article was prepared with the support of the Russian Foundation for Basic Research, appendix 18-29-22004, the topic "Psychological and genetic research of predictors that determine the behavior of users when they perceive Internet content of various informational directions".

\section{References}

1. A. Belousova, U. Mochalova, Behavioral Sciences 10 (3), 68 (2020). DOI: $10.3390 / \mathrm{bs} 10030068$

2. A. Belousova, V. Pishchik, International Journal of Cognitive Research in Science, Engineering and Education (IJCRSEE) 3 (2), 1-8 (2015).

3. O. Fedotova, V. Latun, P. Pivnenko, et al., The state policy in the field of education through the "Hidden pedagogy": a historic event as a factor of national consolidation, 9th annual International Conference of Education, Research and Innovation, 52605265 (2016) DOI : 10.21125/iceri.2016.2275

4. O. Fedotova, E. Nikolaeva, Procedia social and behavioral sciences 185, 785-789 (2015). DOI: 10.1016/j.sbspro.2015.04.010

5. A. Ferraz, Revista eletronica ventilando acervo 8 (2), 27-37 (2020).

6. O. Fedotova, V. Latun, S. Tlepcerishcheva, Based on the novel by OrhanPamuk "The Museum of innocence", Dilemas Contemporaneos-educacion politica y valores 7, 20 (2019).

7. R. Henriques, R. Chaves, Revista eletronica ventilando acervo 8 (2), 75-88 (2020).

8. H. Lee, T. Jung, Information \& management 57 (5), 103229 (2020). DOI: $10.1016 /$ j.im.2019.103229

9. L. Daniela, Sustainability 12 (7), (2020). DOI: 10.3390/su12072698

10. J. Kim, Memory studies 13 (1), 90-106 (2020). DOI: 10.1177/1750698018766386

11. Y. Elias, Public-art culture ideas $26 \quad$ (52), 152-158 DOI: 10.1386/public.26.52.152_7

12. O. Latun Fedotova, V.I. Okuneva, Features of use of the structural components of a creolized text in an ABC-book: trends to conceptual inversion, 9th International Conference on Education and New Learning Technologies, 5269-5273 (2017). DOI: $10.21125 /$ edulearn.2017.2186

13. L. Karasev, Voprosyfilosofii 9, 74-85 (2012)

14. T. Dalziell, Australian literary studies 28(1-2), 163-175 (2013). 
15. L. Cohen, L. Manion, K. Morrison, Research methods in education, 6th edition (Routledge, London and New York, 2008).

16. O. Fedotova, O. Chigisheva, International Perspectives on Education and Society 26, 57-82 (2015). DOI: 10.1108/S1479-367920140000026003

17. J. Freeman, M. Walters, J. Campbell, How to display data (Bleckwell Publishing, Oxford, 2008).

18. I. Cherkashin, E. Krivoruchenko, W. Jagiello, S. Iermakov, Archives of budo science of martial arts and extreme sports 14, 31-43 (2018). 